\title{
RENDIMENTO E COMPOSIÇÃO QUÍMICA DA FORRAGEM DE SORGO EM DIFERENŢES ÉPOCAS DE SEMEADURA
}

\author{
Yield and chemical composition of forage sorghum at different sowing dates
}

\author{
Hélio Peres de Alcântara ${ }^{1}$, Everson Reis Carvalho ${ }^{2}$, Pedro Milanez de Rezende ${ }^{2}$, \\ Jacinto Pereira Santos ${ }^{3}$, Messias José Bastos de Andrade ${ }^{2}$
}

\begin{abstract}
RESUMO
Com o objetivo de avaliar o efeito de épocas de semeadura do híbrido de sorgo silageiro Volumax, foi conduzido um experimento no Campus da Universidade Federal de Lavras, em Lavras/MG, em dois anos agrícolas 2006/07 e 2007/08. O delineamento utilizado foi o de blocos ao caso, com cinco tratamentos e três repetições, compreendendo cinco épocas de semeadura (30 de outubro, 15 e 30 de novembro e 15 e 30 de dezembro). Foram avaliados o rendimento de massa verde, seca e proteína bruta além dos teores de $\mathrm{P}, \mathrm{Ca}, \mathrm{K}, \mathrm{Mg}$ e S na forragem. Os resultados obtidos permitiram constatar decréscimos no rendimento de forragem com o atraso na época de semeadura. A semeadura de 30 de dezembro proporcionou menores teores de nutrientes na forragem do sorgo.
\end{abstract}

Termos para indexação: Sorghum bicolor, silagem, nutrientes, proteína.

\begin{abstract}
To evaluate the effect of sowing dates of hybrid silage sorghum Volumax, an experiment was conducted on the campus of the Universidade Federal de Lavras, Lavras/MG, in two crop years 2006/07 and 2007/08. The design was to block the case, with five treatments and three replicates with five sowing dates (October 30, November 15 and 30 and December 15 and 30). We evaluated the yield of green mass, dry mass and crude protein and levels of $\mathrm{P}, \mathrm{Ca}, \mathrm{K}, \mathrm{Mg}$ and $\mathrm{S}$ in forage. The results revealed a decline in forage yield with delayed sowing date. The sowing of December 30 provided lower levels of nutrients in forage sorghum.
\end{abstract}

Index terms: Sorghum bicolor, silage, nutrient, protein.

(Recebido em 10 de junho de 2009 e aprovado em 7 de fevereiro de 2011)

\section{INTRODUÇÃO}

O sorgo é originário do continente Africano e no Brasil tornou-se uma importante forrageira e, assim, como outras culturas está sujeito a sazonalidade, ocasionando assim baixos índices de produtividade das plantas forrageiras.

As variações ocorridas nas condições climáticas, principalmente na temperatura em diferentes períodos do ano, afetam o desenvolvimento das cultivares de sorgo (MARTIN; VANDERLIP, 1997). Temperaturas elevadas no período entre a diferenciação floral e à floração podem causar o aborto das flores e dos embriões (PAUL, 1990). Por outro lado, temperaturas baixas provocam esterilidade dos grãos de pólen, influenciando o desenvolvimento da panícula. Consequentemente, esses efeitos podem ocasionar diminuição na produção de grãos e decréscimos na qualidade da forragem do sorgo. Ferraris e Charles-Edwards (1986) observaram influência na duração do ciclo e no rendimento de massa seca do sorgo, ocasionado pelo atraso na data de semeadura, diminuindo o número de dias até à antese.
Machado et al. (1987) e Allen e Musick (1993) verificaram que, com o atraso da semeadura do sorgo, os estádios fenológicos foram antecipados. Heckler (2002) constatou que os híbridos de sorgo se comportam de maneira diferenciada, em razão dos efeitos de fotoperíodos e de temperaturas mais elevadas.

De acordo com Pedreira et al. (2003), os híbridos de sorgo apresentam características agronômicas e valor nutritivo diferentes, com consequentes variações quanto à produtividade e padrões de fermentação, resultando em silagens com diferentes qualidades, essas características podem afetar diretamente o desempenho dos animais que consomem o sorgo, tornando evidente a necessidade de estudos que conduzam à seleção de híbridos mais adequados aos sistemas de produção animal. Conforme relata Silva et al. (1990), existem poucas informações relativas às épocas de semeadura, características de produção e valor nutritivo das diversas variedades e ou híbridos de sorgo.

Para Rodrigues Filho et al. (2006), Amaral et al. (2008), Benett et al. (2008) e Santos et al. (2009), pesquisas

\footnotetext{
${ }^{1}$ Universidade Federal de Lavras/UFLA - Departamento de Agricultura/DAG - Cx. P. 37 - 37200-000 - Lavras, MG - hphelioperes@yahoo.com.br ${ }^{2}$ Universidade Federal de Lavras/UFLA - Departamento de Agricultura/DAG - Lavras, MG

${ }^{3}$ Universidade Federal do Tocantins/UFT - Tocantins, TO
} 
sobre a composição mineral em plantas forrageiras vêm merecendo atenção especial por parte da comunidade científica. Esse interesse é justificado pela grande variação regional dos teores médios dos minerais, que podem variar de acordo com a época de semeadura (CHEEKE, 1991). Dentre os minerais mais importantes, tanto em quantidade quanto em qualidade, destacam-se o cálcio, fósforo, potássio, magnésio e enxofre, cujas fontes mais viáveis e econômicas para o fornecimento desses nutrientes são as plantas forrageiras (HOPKINS et al., 1994; GRISS et al., 2008; SIMILI et al., 2008).

Nesse contexto, existem inúmeros relatos comparando o rendimento de grãos ou de forragem do monocultivo, visando a constatar a viabilidade dos híbridos forrageiros desses híbridos no mercado (REDFEARN et al., 1999; SILVA, 2000; REZENDE et al., 2005).

Considerando a importância da produção de forragens de alta qualidade, conduziu-se este trabalho, com o objetivo de avaliar o efeito de diferentes épocas de semeadura, na produção e composição da forragem da cultura do sorgo.

\section{MATERIAL E MÉTODOS}

O experimento foi conduzido no Departamento de Agricultura no Campus da Universidade Federal de Lavras, em Lavras, MG, situada a $21^{\circ} 14^{\prime}$ de latitude Sul e $45^{\circ} 00^{\prime}$ de longitude W.Gr., 918 metros de altitude. O solo foi classificado como Latossolo Roxo distroférrico típico de textura argilosa (EMPRESA BRASILEIRA DE PESQUISA AGROPECUÁRIA - EMBRAPA, 1999), e os resultados das análises químicas da amostra de solo coletada na profundidade de 0-20 cm, na área experimental em 2006/07, realizadas no Instituto de Química "John H. Wheelock" do Departamento de Ciências do Solo da Universidade Federal de Lavras foram: $\mathrm{pH}$ em água 5,4 (médio), $\mathrm{P} 13 \mathrm{mg} / \mathrm{dm}^{3}$ (alto), $\mathrm{K}^{+} 59 \mathrm{mg} / \mathrm{dm}^{3}$ (médio), $\mathrm{Ca}^{2+} 2,9 \mathrm{cmolc} / \mathrm{dm}^{3}$ (médio), $\mathrm{Mg}^{2+} 0,8 \mathrm{cmolc} / \mathrm{dm}^{3}$ (médio), $\mathrm{Al}^{3+} 0,1 \mathrm{cmolc} / \mathrm{dm}^{3}$ (baixo), $\mathrm{H}^{++} \mathrm{Al}^{3+} 3,5 \mathrm{cmolc} / \mathrm{dm}^{3}$ (médio), SB 3,7 cmolc/dm ${ }^{3}$ (médio), $\mathrm{t}$ $3,8 \mathrm{cmolc} / \mathrm{dm}^{3}$ (médio), T $8,9 \mathrm{cmolc} / \mathrm{dm}^{3}$ (médio), m (\%) 2 (baixo), V (\%) 56 (baixo), MO 2,6 dag/kg (alto), interpretações de acordo com Ribeiro et al. (1999). O clima da região, segundo a classificação de Koppen, enquadrase no tipo Cwa (OMETTO, 1981). As temperaturas médias diárias e precipitações pluviométricas, durante o período do experimento, são apresentados na Figura 1.

O experimento foi instalado nos anos agrícolas de 2006/07 e 2007/08, utilizando o híbrido Volumax em parcelas constituídas por três fileiras com $10,0 \mathrm{~m}$ de comprimento espaçadas entre si de $0,8 \mathrm{~m}$, sendo utilizada como área útil a fileira central correspondendo, portanto, a $8,0 \mathrm{~m}^{2}$. O desbaste foi realizado aos 25 dias após a emergência das plântulas, deixando 12 plantas por metro linear. As adubações seguiram as recomendações feitas por Ribeiro et al. (1999), utilizando-se $20 \mathrm{~kg} \mathrm{ha}^{-1}$ de $\mathrm{N}, 80 \mathrm{~kg} \mathrm{ha}^{-1}$ de $\mathrm{P}_{2} \mathrm{O}_{5}$ e $50 \mathrm{~kg} \mathrm{ha}^{-1}$ de $\mathrm{K}_{2} \mathrm{O} \mathrm{kg} \mathrm{ha-1}$ na semeadura e $40 \mathrm{~kg} \mathrm{ha}^{-1}$ de $\mathrm{N}$ em cobertura, aos 45 dias após a emergência das plantas, utilizando como fonte de $\mathrm{N}, \mathrm{P}_{2} \mathrm{O}_{5}$ e $\mathrm{K}_{2} \mathrm{O}$ o sulfato de amônio, o supersimples e o cloreto de potássio, respectivamente.

O delineamento experimental utilizado foi o de blocos casualizados com cinco tratamentos e três repetições, compreendendo cinco épocas de semeadura do sorgo ( 30 de outubro, 15 e 30 de novembro e 15 e 30 de dezembro). Todos os tratos culturais foram realizados uniformemente, sendo o corte realizado uma única vez, rente ao solo, obedecendo à época apropriada da cultura para produção de silagem (grãos farináceos), utilizando roçadeira costal motorizada. Por ocasião dos cortes, foi avaliado o rendimento de massa verde, sendo todas as plantas da parcela útil cortadas e pesadas em balança, sendo o resultado convertido para $\mathrm{kg} \mathrm{ha}^{-1}$.

Posteriormente, foram retiradas amostras de 10 plantas por parcela, que foram trituradas, usando picador de forragem e, posteriormente, homogeneizadas. A partir desse material, foi retirada uma subamostra de $300 \mathrm{~g}$ para a determinação da massa seca, que foi realizada utilizando estufa de circulação forçada de ar à temperatura de $65^{\circ} \mathrm{C}$ até atingir peso constante. Após determinado o valor do teor de massa seca das amostras, foi feita a conversão para $\mathrm{kg} \mathrm{ha}^{-1}$.

A determinação do rendimento de proteína bruta foi realizada a partir do material utilizado para determinação da massa seca. Para isso, após a pesagem, as amostras foram moídas em um moinho tipo Willey, com peneiras de $1,0 \mathrm{~mm}$ de bitola, guardado em recipientes de vidro hermeticamente fechados e devidamente identificados, sendo, posteriormente, enviados ao Laboratório de Análise Foliar da UFLA. O rendimento de proteína bruta foi calculado a partir do teor de nitrogênio, que foi determinado utilizando-se o aparelho de destilação a vapor micro-Kjeldahl (ASSOCIATION OF OFFICIAL ANALYTICALCHEMISTRY AOAC, 1990) e os resultados convertidos para $\mathrm{kg} \mathrm{ha}^{-1}$.

A quantificação dos minerais ( $\mathrm{P}, \mathrm{K}, \mathrm{Ca}, \mathrm{Mg}$ e $\mathrm{S})$ foi realizada a partir das amostras de massa seca, fazendo uso de digestão com ácido nítrico e perclórico e as quantidades no extrato determinados por calorimetria para fósforo, fotometria de chama para potássio, turbimetria para enxofre e espectrometria de absorção atômica para cálcio e magnésio (MALAVOLTA et al., 1997). 
730

ALCÂNTARA, H. P. de et al.
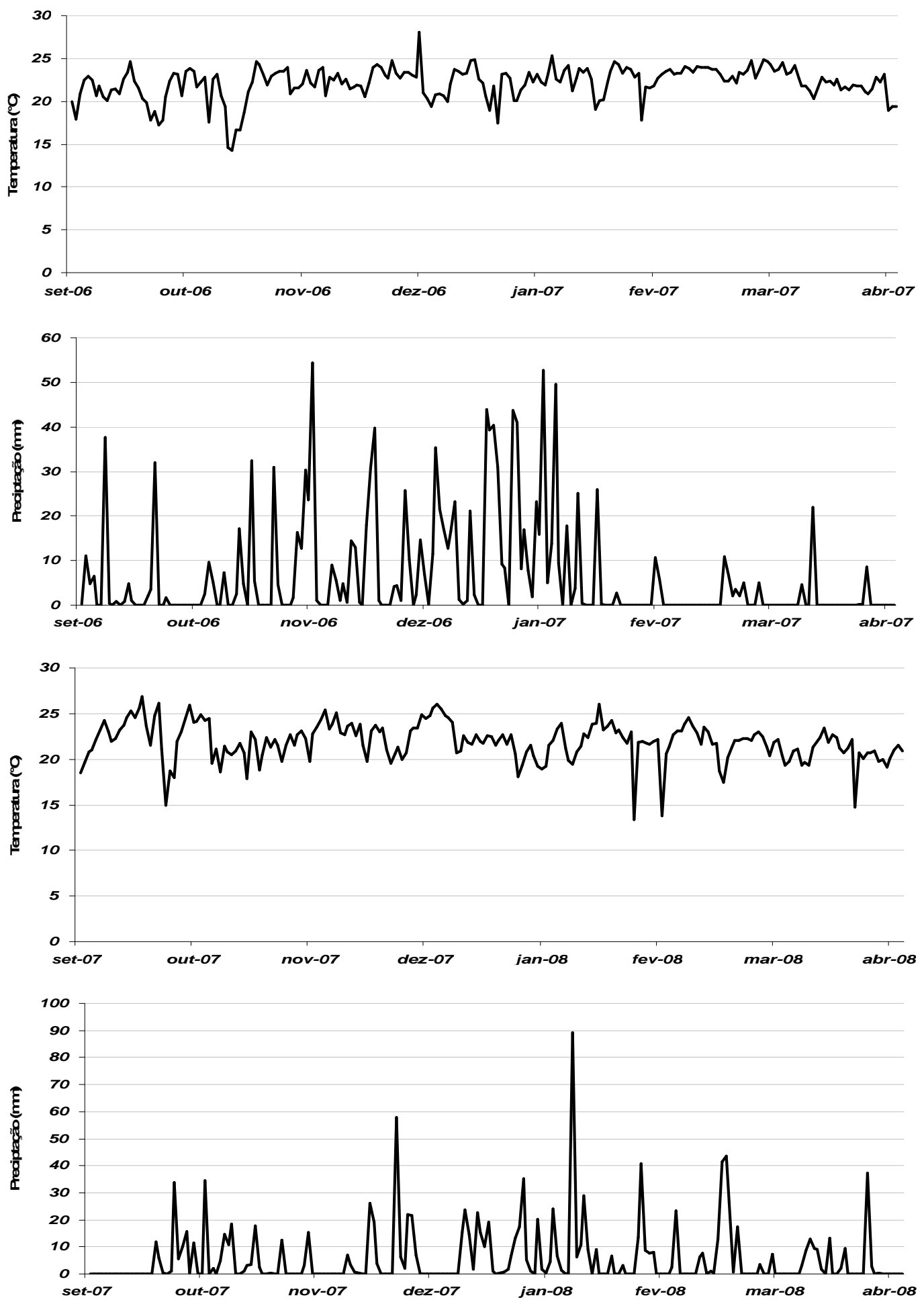

Figura 1 - Representação gráfica da temperatura média diária e precipitação pluviométrica, no período de setembro de 2006 a abril de 2007 e setembro de 2007 a abril de 2008 (dados coletados pela Estação Climatológica Principal de Lavras, MG, UFLA).

Ciênc. agrotec., Lavras, v. 35, n. 4, p. 728-734, jul./ago., 2011 
As análises estatísticas foram realizadas utilizandose o software Sistema de Análise de Variância (SISVAR ${ }^{\circledR}$ ) (FERREIRA, 2008) e as médias foram comparadas utilizando o teste de Scott-Knot a 5\%.

\section{RESULTADOS E DISCUSSÃO}

\section{Rendimento de massa verde, massa seca e proteína bruta}

De acordo com a análise de variância para o rendimento de massa verde, massa seca e proteína bruta verificam-se que as épocas de semeadura alteraram significativamente $(\mathrm{P}<0,01)$ o desempenho das características analisadas (Tabela 1).

As épocas de semeadura ocasionaram mudanças no rendimento de massa verde, observando rendimentos decrescentes à medida que se atrasava a época de semeadura do sorgo (Tabela 2). Pode-se observar que a época de semeadura de 30 de outubro proporcionou maior rendimento de massa verde, sendo o mais baixo valor observado na última época de semeadura. Por esses resultados pode-se inferir que essa característica encontra-se intimamente relacionada com o desenvolvimento vegetativo da planta. Nas épocas mais tardias de semeadura normalmente ocorre diminuição da disponibilidade de água no solo, da temperatura e de insolação no estádio de maturação das plantas. Além disso, a partir da última época de semeadura, o fotoperíodo começa a diminuir, induzindo o meristema apical das plantas de sorgo passarem da fase vegetativa para a fase reprodutiva (SILVA; ROCHA, 2006). Isso conseqüentemente, ocasiona redução no porte da planta e, consequentemente, redução no rendimento de massa seca das plantas (SILVA et al., 2005). Resultados coincidentes a esses foram verificados por Mateus et al. (2005) que estudaram o efeito da época de semeadura, e também constataram antecipação dos estádios de desenvolvimento da planta, à medida que houve atraso na semeadura, e que semeaduras tardias, reduzem o desenvolvimento da planta, tendo como consequência menor produção de forragem.

Com relação ao rendimento de massa seca foi observado um efeito semelhante ao rendimento de massa verde com a obtenção de rendimentos decrescentes com o avanço da época de semeadura (Tabela 2), sendo os maiores valores obtidos nas semeaduras realizadas em 30 de outubro e 15 de novembro. Trabalhos de épocas de semeadura para produção de forragem indicam que semeaduras antecipadas, principalmente no início do período chuvoso, são as mais promissoras para obtenção de maiores rendimentos de forragem com a cultura do sorgo (MATEUS et al., 2005; SILVA et al., 2005; SANTOS et al., 2009).
Para o rendimento de proteína bruta, pode-se observar que todas as épocas de semeadura apresentaram rendimento semelhante entre si com exceção da semeadura em 30 de dezembro no qual se constatou menor valor de rendimento de proteína bruta (Tabela 2). Esses resultados comprovam que o menor porte da planta constatado nas semeaduras mais tardias fizeram com que houvesse menor rendimento de massa seca, e consequentemente, de proteína bruta (SILVA et al., 2006).

De acordo com Mateus et al. (2005) a antecipação dos estádios de desenvolvimento da planta, com o atraso da semeadura, tem como consequência a redução da fase vegetativa, refletindo-se em menor tempo para as plantas entrarem em florescimento. Essa constatação permite inferir que a espécie de sorgo utilizada apresenta sensibilidade ao fotoperíodo, uma vez que, a partir de 24 de dezembro os dias começam a diminuir e a planta é estimulada a florescer diminuindo, consequentemente, o acúmulo de massa seca (SILVA et al., 2005).

\section{Acúmulo de fósforo, cálcio, potássio, magnésio e enxofre}

Por meio do resumo das análises de variância para o acúmulo de minerais na forragem produzida constatouse significância da época de semeadura para todos os minerais avaliados (Tabela 3 ).

Os acúmulos de fósforo, cálcio, magnésio e enxofre na forragem do sorgo foram significativamente alterados pela época de semeadura, sendo observados valores semelhantes nas quatro primeiras épocas de semeadura, sendo superior a semeadura de 30 de dezembro (Tabela 4). Segundo recomendações da National Research Council NRC (1996), os valores médios de fósforo verificados na forragem do sorgo são suficientes para atender às categorias de gado de corte e em lactação, cuja exigência é de 11 a $26 \mathrm{~g} \mathrm{dia}^{-1}$ Para o cálcio, a exigência é de 19 a $58 \mathrm{~g} \mathrm{dia}^{-1}$ e para gado em lactação, a exigência é $0,43 \%$ a $0,77 \%$, acima dos valores encontrados neste estudo. Para o elemento magnésio, a exigência para o gado de corte é de $0,10 \%$ em animais em crescimento e engorda e de $0,20 \%$ para gado leiteiro em início e em lactação. Em relação ao magnésio a exigência para gado em crescimento e engorda é de $0,08-0,15 \%$, e de $0,32 \%$ da massa seca para gado leiteiro. Neste caso, os valores obtidos encontram-se abaixo das exigências dos animais.

O maior acúmulo de potássio na forragem de sorgo foi obtido quando a semeadura foi realizada mais cedo. A época de semeadura 30 de outubro e 15 de novembro destacaram-se das demais com um acúmulo de 174,48 e $178,48 \mathrm{~kg} \mathrm{ha}^{-1}$, superando as épocas 30 de novembro, $15 \mathrm{e}$ 30 de dezembro em 33,96\% (44,24), 40,43\% (50,24), 198,71\% 
Tabela 1 - Resumo da análise de variância para os rendimentos médios de massa verde, massa seca e proteína bruta total $\left(\mathrm{kg} \mathrm{ha}^{-1}\right)$ obtidos no experimento de épocas de semeadura, anos agrícolas 2006/07 e 2007/08, UFLA, Lavras/MG.

\begin{tabular}{ccccc}
\hline \multirow{2}{*}{ Fonte de Variação } & \multirow{2}{*}{ GL } & \multicolumn{3}{c}{ Quadrados médios } \\
\cline { 3 - 5 } & 2 & Massa verde & Massa Seca & Proteína Bruta \\
\hline Blocos & 4 & 39.866 .666 & 4.178 .478 & 19.909 \\
Épocas & 8 & 13.538 .541 & $50.806 .397^{* *}$ & $168.291^{* *}$ \\
Resíduo & 11,57 & 2.141 .402 & 7.032 \\
\hline C.V. $(\%)$ & & & 12,15 & 11,00 \\
\hline
\end{tabular}

**, significativo, pelo teste $\mathrm{F}$, a $1 \%$.

Tabela 2 - Resultados médios de rendimentos de massa verde, massa seca e proteína bruta ( $\left.\mathrm{kg} \mathrm{ha}^{-1}\right)$ obtidos na cultura do sorgo, em função das épocas de semeadura, anos agrícolas 2006/07 e 2007/08. UFLA, Lavras/MG. *

\begin{tabular}{cccc}
\hline Época & Massa Verde & Massa Seca & Proteína Bruta \\
\hline $30 / 10$ & $46.291 \mathrm{a}$ & $16.470 \mathrm{a}$ & $972 \mathrm{a}$ \\
$15 / 11$ & $38.500 \mathrm{~b}$ & $15.444 \mathrm{a}$ & $843 \mathrm{a}$ \\
$30 / 11$ & $31.833 \mathrm{~b}$ & $11.603 \mathrm{~b}$ & $752 \mathrm{a}$ \\
$15 / 12$ & $25.833 \mathrm{c}$ & $10.488 \mathrm{~b}$ & $880 \mathrm{a}$ \\
$30 / 12$ & $16.583 \mathrm{~d}$ & $6.215 \mathrm{c}$ & $362 \mathrm{~b}$
\end{tabular}

*Médias seguidas pela mesma letra na coluna não diferem entre si, pelo teste de Scott-Knott, a 5\% de probabilidade

Tabela 3 - Resumo da análise de variância para os acúmulos médios de fósforo, cálcio, potássio, magnésio e enxofre ( $\mathrm{kg} \mathrm{ha}^{-1}$ ) obtidos na cultura do sorgo, em função das épocas de semeadura, anos agrícolas 2006/07 e 2007/08, UFLA, Lavras/MG.

\begin{tabular}{ccccccc}
\hline \multirow{2}{*}{ Fonte de Variação } & & \multicolumn{5}{c}{ Quadrados Médios } \\
\cline { 3 - 7 } & GL & $\mathrm{P}$ & $\mathrm{Ca}$ & $\mathrm{K}$ & $\mathrm{Mg}$ & $\mathrm{S}$ \\
\hline Blocos & 2 & 6,10 & 63,54 & 374,12 & 21,22 & 2,94 \\
Época (E) & 4 & $93,79^{* *}$ & $656,90^{*}$ & $7.059,06^{* *}$ & $756,11^{* *}$ & $32,35^{* *}$ \\
Resíduo & 8 & 6,21 & 95,40 & 273,61 & 6,58 & 3,42 \\
\hline C.V. $(\%)$ & & 12,92 & 19,52 & 12,43 & 8,87 & 18,10 \\
\hline
\end{tabular}

**, * significativo, pelo teste $\mathrm{F}$, a $1 \%$ e $5 \%$ respectivamente.

Tabela 4 - Valores médios de acúmulo de fósforo, cálcio, potássio, magnésio e enxofre $\left(\mathrm{kg} \mathrm{ha}^{-1}\right)$ obtidos na cultura do sorgo, em função das épocas de semeadura, anos agrícolas 2006/07 e 2007/08, UFLA, Lavras/MG. *

\begin{tabular}{cccccc}
\hline Época & $\mathrm{P}$ & $\mathrm{Ca}$ & $\mathrm{K}$ & $\mathrm{Mg}$ & $\mathrm{S}$ \\
\hline 30/out & $21,63 \mathrm{a}$ & $52,08 \mathrm{a}$ & $174,48 \mathrm{a}$ & $51,42 \mathrm{a}$ & $14,10 \mathrm{a}$ \\
15/nov & $21,70 \mathrm{a}$ & $57,16 \mathrm{a}$ & $178,48 \mathrm{a}$ & $34,43 \mathrm{a}$ & $10,94 \mathrm{a}$ \\
30/nov & $18,14 \mathrm{a}$ & $49,38 \mathrm{a}$ & $130,24 \mathrm{~b}$ & $25,58 \mathrm{a}$ & $11,30 \mathrm{a}$ \\
$15 / \mathrm{dez}$ & $24,79 \mathrm{a}$ & $65,61 \mathrm{a}$ & $124,24 \mathrm{~b}$ & $25,48 \mathrm{a}$ & $9,29 \mathrm{a}$ \\
30/dez & $10,22 \mathrm{~b}$ & $26,00 \mathrm{~b}$ & $58,41 \mathrm{c}$ & $7,74 \mathrm{~b}$ & $5,31 \mathrm{~b}$ \\
\hline
\end{tabular}

* Médias seguidas pela mesma letra minúscula na linha e maiúscula na coluna não diferem entre si, pelo teste de Scott-Knott, a 5\% de probabilidade. 
$(116,07)$ e $37,03 \%(48,24), 43,65 \%(54,24), 205,56 \%(120,07)$ $\mathrm{kg} \mathrm{ha}^{-1}$. O menor acúmulo do mineral foi observado para época de semeadura realizada em 30 de dezembro com um teor médio de $58,41 \mathrm{~kg} \mathrm{ha}^{-1}$. Considerando-se que a exigência desse elemento para o gado de corte é da ordem de 0,60 $0,70 \%$, para animais em crescimento e engorda e $0,75 \%$ da massa seca, para gado leiteiro em início de lactação e em lactação, os valores determinados neste trabalho atendem plenamente às categorias (NRC, 1996).

\section{CONCLUSÕES}

A semeadura realizada em 30 de outubro proporcionou maiores rendimentos de massa verde, seca de proteína bruta além do maior acúmulo de nutriente na parte aérea das plantas.

Maiores rendimentos de massa seca e proteína bruta também foram obtidos na semeadura de 15 de novembro.

A semeadura de 30 de dezembro ocasionou menores teores de nutrientes na forragem do sorgo.

\section{REFERÊNCIAS BIBLIOGRÁFICAS}

ALLEN, R.R.; MUSICK, J.T. Planting date, water management, and maturity length relations for irrigated grain sorghum. Transactions of the ASAE, Amsterdam, v.36, n.4, p.1123-1129, 1993.

AMARAL, P.N.C. et al. Qualidade e valor nutritivo da silagem de três cultivares de milheto. Ciência e Agrotecnologia, Lavras, v.32, p.611-617, 2008.

\section{ASSOCIATION OF OFFICIAL ANALYTICAL} CHEMISTS. Official methods of analysis. 15.ed. Washington, 1990.

BENETT, C.G.S. et al. Produtividade e composição bromatológica do capim-marandu a fontes e doses de nitrogênio. Ciência e Agrotecnologia, Lavras, v.32, n.5, p.1629-1636, set./out. 2008.

CHEEKE, P.R. Applied animal nutritional: feed and feeding. New Jersey: Prentice Hall, 1991. 504p.

EMPRESA BRASILEIRA DE PESQUISA

AGROPECUÁRIA. Centro Nacional de Pesquisa de Solos. Sistema brasileiro de classificação de solos. Brasília, 1999. 412p.

FERRARIS, R.; CHARLES-EDWARDS, D.A. A comparative analysis of the growth of sweet and forage sorghum crops: I., dry matter production, phenology and morphology. Australian Journal of Agricultural

Research, Melbourne, v.37, n.5, p.495-512, 1986.

FERREIRA, D.F. SISVAR: um programa para análises e ensino de estatística. Revista Symposium, Lavras, v.6, p.36-41, 2008.

GRIS, C.F. et al. de. Épocas de corte e cultivares na composição mineral do feno de soja [Glycine $\max (\mathrm{L}$.) Merrill]. Ciência e Agrotecnologia, Lavras, v.32, p.413419, 2008.

HECKLER, J.C. Sorgo e girassol no outono-inverno, em sistema plantio direto, no Mato Grosso do Sul, Brasil. Ciência Rural, Santa Maria, v.32, p.517-520, 2002.

HOPKINS, A.; ADAMSON, A.H.; BOWLING, P.J. Response of permanent and resseded grassland to fertilizer nitrogen: 2., effects on concentration of $\mathrm{Ca}, \mathrm{Mg}$, $\mathrm{Na}, \mathrm{S}, \mathrm{Mn}, \mathrm{Cu}, \mathrm{Co}$ and $\mathrm{Mo}$ in herbage at a range of siles. Grass and Forage Science, Oxford, v.49, n.1, p.9-20, Mar. 1994.

MACHADO, J.R. et al. Épocas de semeadura de sorgo sacarino em São Manuel e Botucatu, Estado de São Paulo. Pesquisa Agropecuária Brasileira, Brasília, v.22, n.9/10, p.951-958, set./out. 1987.

MALAVOLTA, E.; VITTI, G.C.; OLIVEIRA, S.A. Avaliação do estado nutricional das plantas: princípios e aplicações. 2.ed. Piracicaba: Potafós, 1997. 319p.

MARTIN, V.L.; VANDERLIP, R.L. Sorghum hybrid selection and planting management under moisture limiting conditions. Journal of Production Agriculture, Cambridge, v.10, n.1, p.157-163, 1997.

MATEUS, G.P.; CRUSCIOL, C.A.; COSTA, C. Composição físico-química e potencial para ensilagem do sorgo-de-guiné gigante em seis épocas de semeadura. Pesquisa Agropecuária Brasileira, Brasília, v.40, p.935-942, 2005.

\section{NATIONAL RESEARCH COUNCIL. Nutrient} requirement of beef cattle. 7.ed. Washington: National Academy, 1996. 404p.

OMETTO, J.C. Bioclimatologia vegetal. São Paulo: Agronômica Ceres, 1981. 525p. 
PAUL, C.L. Agronomia del sorgo. Patancheru: Icrisat, 1990. 301p.

PEDREIRA, M.S. et al. Características agronômicas e composição química de oito híbridos de sorgo (Sorghum bicolor (L.) Moench). Revista Brasileira de Zootecnia, Viçosa, v.32, p.1083-1092, 2003.

REDFEARN, D.D.; BUXTON, D.R.; DEVINE, T.E. Sorghum intercropping effects on yield, morphology, and quality of forage soybean. Crop Science, Madison, v.39, n.5, p.1380-1384, Sept./Oct. 1999.

REZENDE, P.M. de et al. de. Produção de forragem de cultivares de soja e híbridos de sorgo consorciados na entrelinha, em dois sistemas de corte. Revista Ceres, Viçosa, v.52, n.299, p.59-71, jan./fev. 2005.

RIBEIRO, A.C.; GUIMARÃES, P.G.; VICENTE, V.H.A. Recomendações para o uso de corretivos e fertilizantes em Minas Gerais: $5^{a}$ aproximação. Viçosa, MG: UFV, 1999. 359p.

RODRIGUES FILHO, O. et al. Produção e composição bromatológica de quatro híbridos de sorgo forrageiro [Sorghum bicolor (L.) Moench] submetidos a três doses de nitrogênio. Ciência Animal Brasileira, Goiânia, v.7, n.1, p.37-48, jan./mar. 2006.

SANTOS, J.P. et al. Efeito de sistemas de corte e arranjo de plantas no desempenho forrageiro do sorgo. Ciência e Agrotecnologia, Lavras, v.33, n.2, p.397-404, mar./abr. 2009.
SILVA, A.G. de et al. Consórcio sorgo-soja. I. Produção de forragem de cultivares de soja e híbridos de sorgo, consorciadas na linha, em dois sistemas de corte. Ciência Rural, Santa Maria, v. 30, n. 6, p. 933-939, nov./ dez. 2000.

SILVA, A.G.; ROCHA, V.S. Avaliação dos estágios fenológicos de cultivares de sorgo forrageiro em diferentes épocas de semeadura. Pesquisa Agropecuária Tropical, Goiânia, v.36, n.2, p.113-121, 2006.

SILVA, A.G. et al. Avaliação dos caracteres agronômicos de cultivares de sorgo forrageiro sob diferentes condições termo-fotoperiódicas. Revista Brasileira de Milho e Sorgo, Sete Lagoas, v.4, n.1, p.28-44, 2005.

SILVA, A.G. et al. Avaliação do rendimento de forragem de cultivares de sorgo forrageiro sob diferentes condições termo-fotoperiódicas. Revista Ceres, Viçosa, v.53, n.307, p.292-301, 2006.

SILVA, J.F.C. da et al. Idade de corte do sorgo Santa Eliza (Sorghum vulgare, Pers.), para silagem: I., produção e característica das silagens. Revista da Sociedade Brasileira de Zootecnia, Viçosa, v.19, n.2, p.98-105, mar./ abr. 1990.

SIMILI, F.F. et al. Resposta do híbrido de sorgo-sudão à adubação nitrogenada e potássica: composição química e digestibilidade in vitro da matéria orgânica. Ciência e Agrotecnologia, Lavras, v.32, n.2, p.474-480, mar./abr. 2008. 